\title{
Pemodelan SCRUM dalam Pengembangan Sistem Informasi Kesehatan pada Klinik Ar-Rokhim Sragen Kabupaten Sragen
}

\author{
SCRUM Model on Development of Health Information System at Ar-Rokhim Clinic in \\ Sragen Regency
}

\author{
Ikhwansyah Kurniawan ${ }^{1}$, Ramadhan Rakhmat Sani ${ }^{2}$ \\ ${ }^{1,2}$ Fakultas Ilmu Komputer, Universitas Dian Nuswantoro Semarang \\ e-mail: ${ }^{1}$ kurniawan.ikhwansyah@gmail.com, ${ }^{2}$ ramadhan_rs@dsn.dinus.ac.id
}

\begin{abstract}
Abstrak
Proses bisnis pada klinik Ar-Rokhim pada bagian pendaftaran, pencatatan rekam medis pasien, penjualan obat, pembuatan laporan dan penghitungan biaya rawat belum memaksimalkan aplikas sistemi yang ada. Hal ini membuat proses bisnis yang dilakukan oleh klinik kurang efektif. Salah satu metode pengembangan sistem yang sering digunakan untuk mengembangkan sistem yaitu waterfall, metode ini memiliki kekurangan karena tidak diperkenankan adanya perubahan pada siklus pengembangan, membutuhkan tim yang banyak dan waktu pengembangan yang cukup lama. Untuk itu pada penelitian ini menggunakan salah satu Agile sofware development yaitu SCRUM model. Selain memiliki kelebihan requiredment yang fleksibel, jumlah anggota tim yang diperlukan tidak banyak. Tujuan dari penelitian ini ialah untuk menghasilkan pengembangan sistem informasi dengan cepat dalam penyesuaian perubahan dan sesuai dengan target yang diharapkan. Dalam pembangunan sistem ini menggunakan bahasa pemrograman PHP, dengan basis data MySql. Pada sisi server menggunakan xampp sebagai penyimpanan database dan website. Untuk menguji produk yang dibuat menggunakan black box testing. Sedangkan untuk menguji efektifitas metode pengembangan menggunakan burdown chart. User Acepptance Testing dilakukan untuk menguji sistem dari sisi calon pengguna sistem.
\end{abstract}

Kata kunci : agile software development, scrum, black box testing, burdown chart

\begin{abstract}
The business process at the Ar-Rokhim clinic in the registration section, recording the patient's medical record, drug sales, reporting and calculation of care costs have not maximized the existing system application. This makes the business processes carried out by the clinic less effective. One method of system development that is often used to develop systems is the waterfall, this method has disadvantages because there is no change in the development cycle, it requires a lot of teams and a long development time. For this reason, one of the Agile software development uses SCRUM model. In addition to having the required excess flexibility, the number of team members needed is not much. The purpose of this research is to produce information system development quickly in adjusting changes and in accordance with expected targets. In the construction of this system using the PHP programming language, with MySql database. On the server side using Xampp as a database and website storage. To test products that are made using black box testing. Whereas to test the effectiveness of the development method using burdown chart. User Acceptance Testing is done to test the system from the side of the prospective user of the system.
\end{abstract}

Keyword : agile software development, scrum, black box testing, burdown chart 


\section{PENDAHULUAN}

Proses bisnis dalam klinik Ar-Rokhim sudah memakai sebuah sistem yang seharusya bisa membatu dalam kegiatannya, namum masih saja terdapat proses yang masih menggunakan cara manual. Beberapa diantaranya yaitu pencatatan data rekam medis pasien, pendaftaran pasien, pembuatan laporan dan penghitungan biaya rawat pasien [1]. Pencatatan rekam medis yang dilakukan secara manual membuat petugas harus mencari data pasien pada buku besar, dimana dalam mencarinya membutuhkan waktu yang tidak sebentar. Penyimpanan data rekam medis hanya berupa hardcopy membuat data rentan mengalami kerusakan dan kehilangan data [2]. Hal ini menjadi penyebab antrian yang lama. Selain itu akumulasi biaya rawat pasien yang dilakuakan menggunakan kalkulator membuat pasien merasa khawatir dengan jumlah perhitungan biaya yang salah. Pengembangan sistem informasi yang berbasis komputer membutuhkan waktu dalam proses pengembangannya. Hal ini dikarenakan terdiri dari tugas-tugas yang kompleks yang membutuhkan banyak sumber daya. Proses pengembangan sistem melewati beberapa tahapan dari mulai sistem itu direncanakan sampai dengan sistem tersebut dimplemnetasikan, dioperasikan dan dipelihara. Bila operasi sistem yang telah dikembangkan masih memiliki permasalahan-permasalahan yang kritis serta tidak dapat diatasi dalam tahapan pemeliharaan sistem, maka butuh dikembangkan kembali suatu sistem untuk mengatasinya dan proses ini kembali ke tahap yang pertama (perencanaan sistem). Siklus demikian merupakan siklus hidup suatu sistem (system life cycle), suatu bentuk yang digunakan untuk menggambarkan tahapan utama dan langkah-langkah di dalam tahapan tersebut dalam proses pengembangannya [3].

Dalam rangka untuk melakukan pengembangan sistem pada saat ini dapat dilakukan dengan beberapa metode. Salah satu metode yang sudah lama digunakan yaitu metode Waterfall. Selain mudah digunakan dan sudah banyak orang yang mengetahuinya, metode ini cocok digunakan pada project yang tidak mengalamai perubahan dalam pengembangannya. Hal ini dikarenakan untuk melakukan perubahan produk terhadap keinginan client sangat sulit dan relatif mahal [4]. Selain Waterfall terdapat metode Spiral, model ini lebih menekankan pada analisis risiko. Model spiral memiliki empat fase: perencanaan, analisis risiko, teknik dan evaluasi. Kelebihan menggunakan metode ini yaitu, perangkat lunak diproduksi pada awal siklus hidup dan memiliki analisis resiko yang tinggi. Penggunaan metode ini sesuai untuk proyek berskala besar. Meskipun demikian dalam pengembangan, metode spiral mahal untuk digunakan dan untuk melakukan analisis risiko membutuhkan keahlian yang sangat spesifik. Selain itu, keberhasilan proyek sangat tergantung pada fase analisis risiko dan metode ini tidak berjalan dengan baik untuk proyek dengan skala kecil [4]. Sehingga menjadikan permasalahan yang dihadapi dalam pengembangan sistemnya di klinik Ar-Rakhim.

Pada penelitian [5] scrum dapat membantu semua pemangku kepentingan dalam memahmi proyek sehingga proyek sesuai dengan perencanaan hingga tahap implementasi dan dapat secara mudah mengontrol task. Penerapan model agile juga digunakan dalam pengembangan e-trace alumni yang didasari pada masalah kecepatan pengembangan dan terbatasanya tools untuk membatu prosen pengembangannya [6]. Sebagaimana pada [7] memberikan kemudahan peserta didik baru dalam melakukan pendaftaran di SMK 17 Agustus Genteng Banyuwangi sehingga dapat mempermudah panitia dalam mengelola peserta didik yang terdaftar dari SMP/MTs. Dalam [8] scrum digunakan untuk pengembangan aplikasi penjadwalan wisata pada smartphone yang dibangun secara cepat dalam menghadapi perubahan terhadap requirement ataupun permasalahan yang muncul.

Dalam penelitian ini, pengembangan sistem dilakukan menggunakan agile method dengan model Scrum. Secara umum, agile method adalah proses yang menerapkan siklus pendek berulang, secara aktif melibatkan pengguna untuk membangun, memprioritaskan, dan memverifikasi kebutuhan, dan bergantung pada pengetahuan tacit tim menggantikan dokumentasi [9], [10]. Model ini merupakan suatu kerangka kerja untuk mengembangkan produk dimana pertama mulai digunakan pada tahun 1990, metode Scrum digunakan untuk mengelola pengembangan produk yang kompleks [11]. Scrum yang Ditargetkan memiliki efek yang dapat diabaikan pada peningkatan tim pengembangan perangkat lunak komunikasi eksternal dan 
internal. Akhirnya, Targeted Scrum tidak berdampak pada kualitas produk oleh tim berkinerja terbaik dan berkinerja terburuk [12]. Untuk menerapkan Scrum pada pengembangan software diperlukan tim dan peranperanya, acara (sprint, scrum dailly), artefak (Produk Backlog, Sprint Backlog dan Inkremen) serta aturan main [12]. Masing-masing komponen yang berada pada Scrum memiliki sasaran dan fungsi tertentu yang mendukung keberhasilan dari jalannya proses Scrum. Tim Scrum tersusun dari Pemilik Produk (Product Owner), Tim Pengembang (Team Developer), dan seorang Scrum Master. Product owner memiliki tanggung jawab terhadap nilai bisnis dari produk yang diciptakan. Tugas dari Scrum Master memastikan tim yang ikut untuk mengerjakan project dapat bekerja secara produktif dalam membantu tim untuk memenuhi kendala kualitas dan waktu proyek [13]. Sedangkan Tim Pengembang berusaha untuk menyelesaikan pekerjaan yang telah disepakati. Tim ini bertugas dalam membuat produk [10] .

\section{METODELOGI PENELITIAN}

Dalam motedelogi penelitian ini menggunakan pemodelan Scrum yang digambarkan pada Gambar 1 yang menjelaskan tentang urutan atau tahapan kerangka scrum.

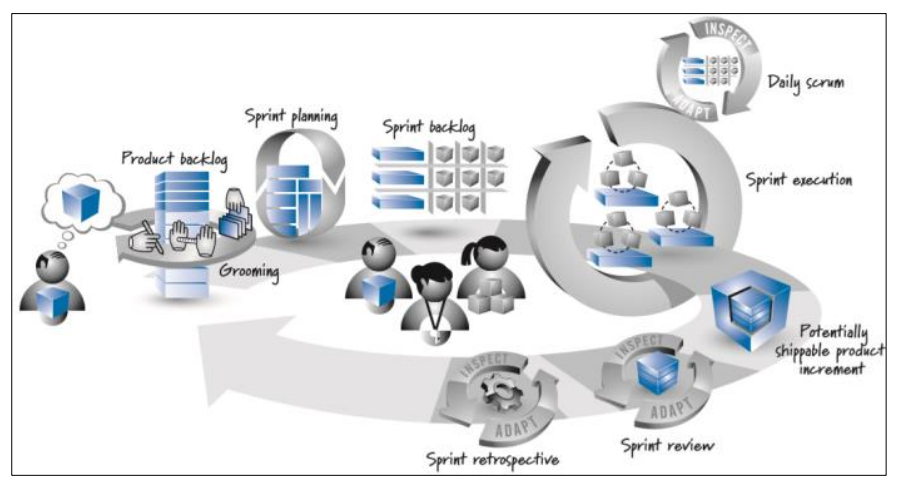

Gambar 1. Kerangka Scrum [14]

a. User Stories

Pada metode Scrum, rincian persyaratan dinegosiasikan melalui diskusi yang terjadi secara berulang selama pengembangan [10]. User stories digunakan untuk membuat Product backlog. Dalam user stories berisi nama pengguna sitem, fitur-fitur yang menjadi kebutuhan sistem dan tujuan dari fitur yang direncanakan. Dengan adanya user stories tim teknis dan tim bisnis dapat berkomunikasi dengan mudah karena bahasa yang digunakan sangat umum.

b. Product Backlog

Pada tahapan ini pekerjaan-pekerjaan yang akan dilakukan ditulis dan dijelaskan oleh Product Owner pada Product Backlog. Pekerjaan yang akan dilakukan memiliki prioritas dalam pengerjaan. Kebutuhan customer dan kebutuhan secara teknikal sebagai acuan untun menentukan priortas pengerjaan. Selain itu prioritas juga dapat ditentukan berdasarkan hal yang dinilai krusial atau penting dengan sistem yang akan dibangun. Untuk menentukan priritas Product Owner dapat meminta pendapat dari tim Scrum atau stakeholders.

c. Sprint Backlog

Pekerjaan-pekerjaan dari Product Backlog didiskusikan dan disepakati oleh tim untuk dimasukan pada Sprint. Proses ini merupakan hasil perpindahan dari prioritas tertinggi dari Product Owner yang kemudian akan dikembangkan melalui Sprint. Proses ini juga dapat disebut sebagai inputan awal sebelum melakukan proses Sprint pada pengembangan produk.

d. Sprint

Sprint memiliki durasi waktu yang konsisten sepanjang masa pengembangan produk. Setelah sprint selesai maka langsung mengerjakan Sprint berikutnya. Sprint memiliki dan terdiri 
dari Sprint Planning, Daily Scrums, The development work (pengembangan), Sprint review, dan Sprint Retrospective.

e. Review dan Demo Product

Tujuan dari kegiatan review dan demo produk adalah untuk memeriksa dan menyesuaikan produk yang sedang dibangun. Kegiatan pada taha ini adalah komunikasi antarara tim Scrum dengan pihak klinik. Percakapan difokuskan pada peninjauan fitur yang baru saja selesai dalam konteks upaya pengembangan secara keseluruhan. Pada tahap ini pihak klinik dapat mengajukan perbaikan jika dimungkin. Komunikasi yang berlangsung disertasi dengan demo produk atau sistem yang sudah dibuat. Tahan demo aplikasi yang dimaksud yaitu tim menyerahkan perangkat lunak atau produk increment kepada client dengan cara melakukan demonstrasi dan client melakukan evaluasi terhadapt produk.

\section{f. Delivery Product}

Tahap dimana produk sudah selesai dibuat dan dalam kondisi useable. Tahap ini merupakan hasil dari Sprint yang selesai dikerjakan berdasarkan Product Backlog. Konsumen atau pemakai sudah sesuai dengan hasil sprint yang dilakukkan pada masing-masing item. Sehingga produk dapat digunakan oleh $u s e r$.

\section{HASIL DAN PEMBAHASAN}

\section{User Stories}

Dalam penggunaan metode Scrum hal yang harus ditentukan oleh Product Owner adalah user stories. User stories digunakan untuk membuat backlog. Dalam user stories berisi nama pengguna sitem, fitur-fitur yang menjadi kebutuhan sistem dan tujuan dari fitur yang direncanakan. User stories dibuat dengan bahasa pengguna secara umum. Hal ini difungsikan agar mudah dimengerti oleh orang bisnis dan orang teknis. Salah satu hal yang paling penting dengan adanya user stories ini ialah kalaborasi antara orang teknis dan orang bisnis untuk mencapai harapan dari pengembangan software.

User Stories Petugas

a. Sebagai seorang petugas klinik, saya ingin kinerja saya lebih efektif. Ketika melakukan pendaftaran saya ingin memasukan data pasien yang belum pernah berkunjung ke klinik. Pasien yang sudah pernah berkunjung dan klinik memiliki datanya, tidak perlu saya masukan lagi.

b. Sebagai seorang petugas klinik, saya ingin data pendaftaran dapat dicetak menjadi nomor antrian dan dapat dihapus.

c. Sebagai seorang petugas klinik, saya ingin mencari dan menghapus data pasien rawat jalan.

d. Sebagai seorang petugas klinik, saya ingin memiliki sistem kasir untuk akumulasi biaya rawat jalan. Setelah memasukan data saya dapat mencetak total biaya dan detailnya.

User stories Apoteker

a. Sebagai seorang apoteker saya ingin mencetak dan menghapus data penjualan obat.

b. Sebagai seorang apoteker saya ingin melayani transaksi penjualan obat. Data obat dan harga secara otomatis muncul ketika transaksi.

User stories Admin

a. Sebagai seorang admin saya ingin melakukan proses yang bisa dilakukan oleh petugas dan apoteker.

b. Sebagai seorang admin, saya ingin menambah, mengubah dan menghapus data dokter.

c. Sebagai seorang admin, saya ingin menambah, mengubah dan menghapus pengguna yang dapat masuk ke sistem.

d. Sebagai seorang admin, saya ingin mencari, menambah, mengubah dan menghapus data tindakan.

e. Sebagai seorang admin, saya ingin melihat laporan data penjualan obat, pendaftaran dan rawat jalan pasien perperiode. 


\section{Pembuatan Product Backlog}

Tahap pembuatan product backlog merupakan pembagian atau pengelompokan prosesproses berdasarkan dari analisis pada langkah sebelumnya. Dokumen ini memiliki isi estimasi pengerjaan, fitur yang akan dibuat dan prioritas dari masing-masing fitur yang ditampilkan pada tabel 1. Berdasarkan langkah pada user stories, maka product backlog ini dibagi menjadi tiga kategori pengguna sistem, yaitu admin, petugas dan apoteker. Setiap fitur backlog memiliki prioritas, hal ini ditentukan berdasarkan tingkat urgent dari kebutuhan dari pengguna. Prioritas menentukan fitur mana yang harus dikerjakan terlebih dahulu. Selain prioritas hal yang diperhatikan yaitu pembagian waktu pengerjaan fitur Backlog dalam Sprint. Prioritas dan panjang sprint ditentukan oleh kesepakatan antara perwakilan tim pengembang, scrum master dan product owner.

Tabel 1. Backlog Products

\begin{tabular}{|c|c|c|c|}
\hline No. & Fitur & Estimasi & Priority \\
\hline \multirow[t]{5}{*}{1.} & Login multi user & 8 & High Priority \\
\hline & Dashboard pengguna sistem & 9 & Low Priority \\
\hline & Pengguna Level Apoteker & & \\
\hline & Mengelola data obat & 14 & Medium Priority \\
\hline & Mengelola penjualan obat & 22 & High Priority \\
\hline \multirow[t]{4}{*}{2} & Pengguna level petugas & & \\
\hline & Mengelola pendaftaran pasien & 15 & High Priority \\
\hline & Mengelola pasien rawat jalan & 29 & High Priority \\
\hline & Mengelola data pasien & 22 & High Priority \\
\hline \multirow[t]{8}{*}{3.} & Pengguna level admin & & \\
\hline & Mengelola data pasien & 22 & High Priority \\
\hline & Mengelola data tindakan & 12 & High Priority \\
\hline & Mengelola data pengguna sistem & 12 & Low Priority \\
\hline & Mengelola data obat & 14 & High Priority \\
\hline & Mengelola data dokter & 12 & Medium Priority \\
\hline & Pembuatan laporan & 18 & Medium Priority \\
\hline & Mengelola penjualan obat & 22 & High Priority \\
\hline \multirow[t]{3}{*}{4.} & Pengguna level apoteker & & \\
\hline & Mengelola data obat & 14 & Medium Priority \\
\hline & Mengelola penjualan obat & 22 & High Priority \\
\hline
\end{tabular}

\section{Melakukan Sprint}

Tahap selanjutnya setelah Product Backlog dibuat yaitu melakukan Sprint. Tiap Sprint memiliki waktu yang hampir sama. Dalam melakukan sekali sprint tidak boleh terlalu lama. Untuk proyek yang besar maksimal sekali sprint 30 hari [14]. Alasan dalam sekali sprint waktunya dibatasi yaitu dengan waktu yang singkat segala kemungkinan mudah untuk diprediksi. Selain itu ruang lingkup yang kecil mudah untuk dikontrol.

Dalam melakukan sprint, terdapat beberapa tahapan pengerjaan yaitu sprint planing, sprint backlog, sprint execution, daily scrum, sprint review dan sprint retrospective. Pada penelitian ini pengembangan sistem dilakukan Sprint sebanyak empat kali. Sprint pertama lebih fokus pada tampilan awal dan bentuk dari website yang dibangun. Dalam hal ini Sprint yang akan dikerjakan meliputi login multi-user dan pembuatan dashboard masing-masing pengguna. Karena menurut perhitungan jumlah waktu untuk menyelesaikannya terlalu singkat maka ditambah proses ativitas yang dilakukan oleh pengguna apoteker. Sprint kedua yang dikerjakan pada sistem ini yaitu fiturfitur pada halaman petugas klinik. Fitur tersebut meliputi pengelolaan data pasien, pendaftaran pasien dan penanganan rawat pada pasien. Sprint selanjutnya yaitu sprint ketiga, pada sprint ini tim mengerjakan fitur pada halaman pengguna admin. Untuk mengerjakan seluruh fitur-fitur pada pengguna admin memerlukan waktu yang terlalu panjang untuk sekali sprint. Oleh karena itu perlu adanya pembatasan ruang lingkup fitur pada sprint ketiga. Ruang lingkup sprint yang tidak 
dikerjakan pada sprint ketiga dikerjakan pada sprint keempat. Jadi untuk mengerjakan fitur backlog yang ada di halaman pengguna admin memerlukan sprint ketiga dan sprint keempat.

a. Sprint planing

Pada sprint yang pertama ini ada tiga fitur yang disepakai yaitu pembuatan login multi-user, fiturfitur pada halaman pengguna apoteker dan pembuatan dashboard pada masing-masing pengguna. Pada halaman pengguna apoteker memiliki fitur mengelola data obat dan mengelola penjualan obat. Setelah menentukan fitur backlog selanjutnya membaginya ke bagian-bagian lebih kecil. Proses ini akan diuraikan pada tahap Sprint Backlog.

b. Sprint Backlog

Sprint backlog berisi penjabaran fitur-fitur backlog menjadi task-task yang lebih detail. Hal ini difungsikan untuk mempermudah tim pengembang dalam menyelesaikan Sprint. Berdasarkan sprint planing yang telah dilakukan. Tabel 2 berisi penjabaran dari produk backlog menjadi bagian-bagain yang lebih sederhana, sehingga memudahkan pengembang dalam membagai pekerjaan. Tabel ini akan dikerjakan pada Sprint yang pertama. Untuk menggambarkan sistem yang akan dibuat pada Sprint pertama menggunakan perancangan database seperti pada gambar 2.

Tabel 2. Sprint Backlog

\begin{tabular}{|c|c|}
\hline Fitur backlog & Task \\
\hline Login multi-user & Halaman utama sebelum masuk ke form login \\
\hline \multirow{4}{*}{$\begin{array}{l}\text { Dashboard } \\
\text { pengguna sistem }\end{array}$} & Dashboard Admin \\
\hline & Dashboard Petugas \\
\hline & Dashboard Apoteker \\
\hline & Membuat Grafik \\
\hline \multicolumn{2}{|c|}{ Pengguna sistem level apoteker } \\
\hline \multirow{4}{*}{ Mengelola data obat } & Menambah data obat \\
\hline & Menghapus data obat \\
\hline & Mengubah data obat \\
\hline & Mencari data obat \\
\hline \multirow{4}{*}{$\begin{array}{l}\text { Mengelola } \\
\text { penjualan obat }\end{array}$} & Melakukan transaksi penjualan obat \\
\hline & Melihat data penjualan obat \\
\hline & Apoteker dapat melakukan cetak nota penjualan obat \\
\hline & Menghapus penjualan obat \\
\hline
\end{tabular}

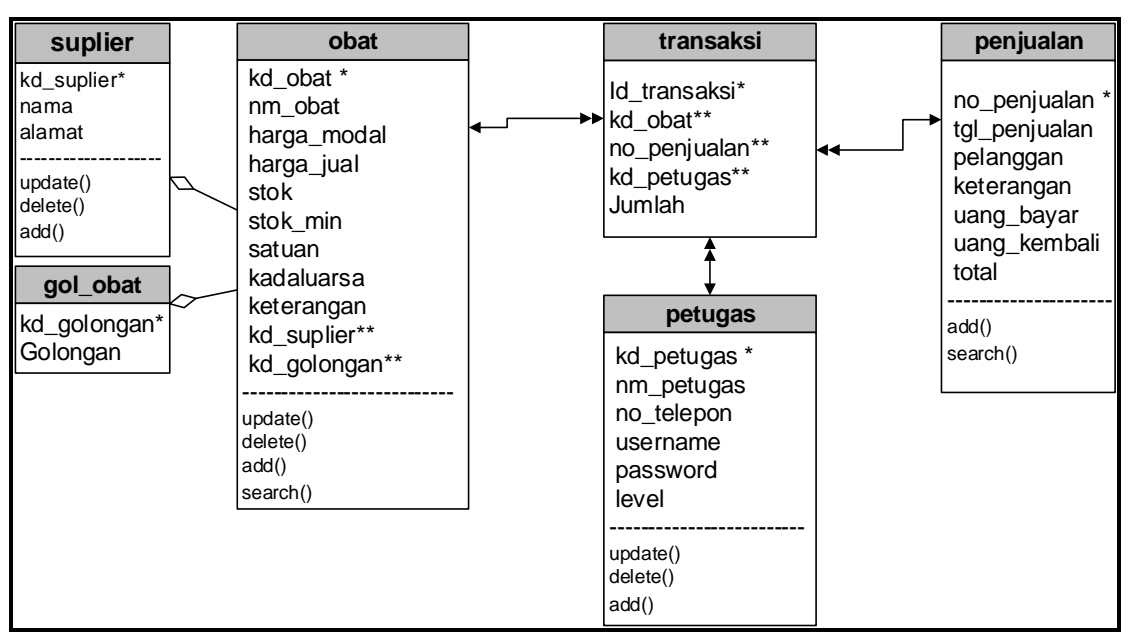

Gambar 2. Perancangan Database Sprint 1 


\section{c. Sprint Execution dan Daily Scrum}

Tahap ini merupakan kelanjutan dari tahap untuk menentukan sprint backlog. Ketika sprint backlog sudah disepakati pada sprint planing maka mulailah melakukan pengembangan sprint backlog tersebut. Proses ini dilakukan untuk mencapai tujuan dari masing-masing sprint backlog. Keluaran dari proses ini berupa rilis produk. Tabel 3 menjelaskan status sprint backlog pada saat proses pengerjaan task hasil penjabaran dari produk backlog. Dari tabel ini dapat diperoleh status dari masing-masing task setiap hari.

Tabel 3. Status Sprint Backlog pada Sprint Execution

\begin{tabular}{|c|c|c|c|c|}
\hline Fitur Backlog & Task & Est. & Dur. & Status \\
\hline \multirow{2}{*}{ Login multi-user } & $\begin{array}{l}\text { Pengguna mengakses halaman utama } \\
\text { sebelum sebelum masuk ke form login }\end{array}$ & 3 & 3 & Done \\
\hline & $\begin{array}{l}\text { Semua pengguna sistem masuk ke sistem } \\
\text { menggunakan satu form }\end{array}$ & 5 & 6 & Done \\
\hline \multirow{4}{*}{$\begin{array}{c}\text { Dashboard } \\
\text { pengguna sistem }\end{array}$} & Dashboard Admin & 3 & 5 & Done \\
\hline & Dashboard Petugas & 3 & 3 & Done \\
\hline & Dashboard Apoteker & 3 & 3 & Done \\
\hline & Membuat Grafik & 5 & 7 & Done \\
\hline \multicolumn{5}{|c|}{ Pengguna sistem level apoteker } \\
\hline \multirow{4}{*}{$\begin{array}{c}\text { Mengelola data } \\
\text { obat }\end{array}$} & Menambah data obat & 3 & - & In Progres \\
\hline & Menghapus data obat & 3 & - & In Progres \\
\hline & Mengubah data obat & 3 & - & In Progres \\
\hline & Mencari data obat & 5 & - & In Progres \\
\hline \multirow{4}{*}{$\begin{array}{c}\text { Mengelola } \\
\text { penjualan obat }\end{array}$} & Melakukan transaksi penjualan obat & 13 & - & Not Started \\
\hline & Melihat data penjualan obat & 3 & - & Not Started \\
\hline & $\begin{array}{l}\text { Apoteker dapat melakukan cetak nota } \\
\text { penjualan obat }\end{array}$ & 3 & - & Not Started \\
\hline & Menghapus penjualan obat & 3 & - & Not Started \\
\hline
\end{tabular}

Pada sprint execution, tahap pengembangan sistem yaitu testing terhadap fitur dilakukan. Hal ini dilakukan untuk menguji fungsi sistem. Pada penelitian ini pengujian yang dilakukan yaitu black box testing. Tabel 4 hasil dari pengujian yang dilakukan pada form dan fungsi dari setiap menu sistem. Testing yang dilakukan meliputi fungsi validasi dari form dan hasil tampilan dari setiap menu.

Tabel 4. Sekenario dan Hasil Pengujian pada Sprint 1

\begin{tabular}{llll}
\hline No. & Skenario pengujian & Output yang diharapkan & Validasi \\
\hline 1. & $\begin{array}{l}\text { Pengguna memasukan } \\
\text { username dan password } \\
\text { dengan benar }\end{array}$ & $\begin{array}{l}\text { Halaman akan berpindah ke dashboard } \\
\text { masing-masing pengguna }\end{array}$ & Sukses \\
2. & $\begin{array}{l}\text { Pengguna memasukan } \\
\text { username dan password yang } \\
\text { salah }\end{array}$ & $\begin{array}{l}\text { Tidak masuk ke halaman dashboard dan } \\
\text { muncul notifikasi error. }\end{array}$ & Sukses \\
3. $\begin{array}{l}\text { Pengguna memasukkan data } \\
\text { pada form transaksi } \\
\text { penjualan dengan benar } \\
\text { User menambahkan data } \\
\text { lebih dari satu obat pada } \\
\text { halaman transaksi }\end{array}$ & $\begin{array}{l}\text { Data tersimpan dalam database dan tampil } \\
\text { pada halaman penjualan }\end{array}$ & Sukses \\
Jumlah total biaya obat secara otomatis & Sukses \\
\hline
\end{tabular}




\section{d. Rilis Produk}

Pada tahap sprint pertama ini telah dikerjakan selama 71 jam. Waktu ini lebih dari waktu estimasi di awal yang diperkirakan dapat dikerjakan selama 63 jam. Dalam pengerjaan, tim memiliki waktu kerja efektif sebanyak 6 jam per harinya. Selama waktu tersebut tim mampu mengerjakan 4 fitur backlog. Pada tabel sprint backlog ini dipaparkan mengenai pembagian dari masing-masing fitur backlog. Setiap task atau pembagian yang dilakukan memiliki estimasi, durasi dan status tertentu. Pada rilis produk ini status yang digunakan harus sudah dalam kategori Done atau sudah selesai dikerjakan. Jika semua fitur backlog sudah selesai dikerjakan maka sprint pertama dapat dinyatakan selesai.

e. Sprint Review

Sprint review dilakukan setelah suatu produk atau feature selesai dibuat dalam sprint execution dan menghasilkan rilis produk. Tujuan dari sprint review ini ialah melihat status dari fitur produk yang telah selesai dikembangkan. Pada tahap ini pihak yang terlibat yaitu product owner, scrum master, tim pengembang dan pengguna sistem. Dalam acara ini tim pengembang melakukan demontrasi mengenai fitur produk yang telah dibuat pada pihak yang hadir dalam acara. Orang yang harus memfasilitasi pada acara ini ialah scrum master. Setelah melakukan demontrasi, pihak-pihak yang terlibat menangapi mengenai fitur tersebut. Jika terdapat penambahan fungsi atau fitur maka akan ditambahkan pada sprint selanjutnya.

\section{f. Sprint Retrospective}

Sesuai pada landasan teori yang digunakan, setelah dilakukan sprint review proses selanjutnya yaitu melakukan sprint retrospective. Proses ini hanya dihadiri oleh tim Scrum. Dalam pertemuan membahas mengenai apa saja yang telah dilakukan untuk menyelesaikan sprint pertama, adakah hambatan yang terjadi untuk menyelesaikan sprint pertama dan bagaimana cara untuk menyelesaikan sprint selanjutnya.

Dari hasil pertemuan diperoleh hasil bahwa semua tim terlibat dalam pemenuhan sprint yang pertama. Untuk mengerjakannya tim memiliki hambatan pada estimasi yang digunakan pada saat sprint berlangsung. Ada beberapa fitur yang tidak sesuai estimasi. Hal ini dikarenakan kurangnya pengetahuan yang mendalam dari tim mengenai fitur yang akan dibuat. Selain itu kurangnya respon yang cepat dan kontribusi dari anggota tim membuat proses pengerjaan sedikit terganggu. Hal ini juga dipengaruhi oleh tim yang terlibat belum memahami tentang implementasi metode Scrum yang digunakan. Hal yang lebih ditekankan pada sprint selanjutnya yaitu sebelum membuat estimasi pengerjaan perlu mengetahui lebih detail mengenai fitur yang akan dibuat. Pengetahuan setiap anggota tim perlu diperdalam mengenai metode pengembangan yang dilakukan. Serta membuat anggota tim yang slow respon untuk segera tanggap ketika dibutuhkan anggota tim yang lainnya.

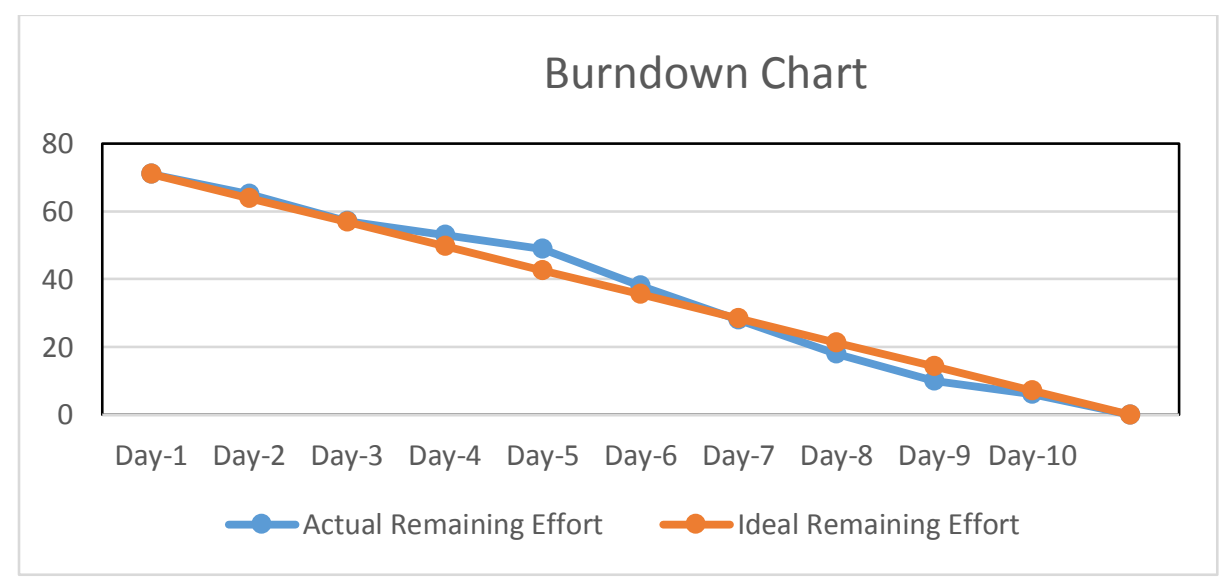

Gambar 3. Burndown Chart 
Penjelasan Burndown Chart pada gambar 3 adalah penggunaan sumbu Y sebagai time unit, dimana sumbu Y digunakan untuk mengetahui sisa waktu yang tersedia untuk menyelesaikan sprint. Sedangkan sumbu $\mathrm{X}$ beriisi hari yang digunakan untuk melakuakn sprint. Pada sprint yang pertama ini jumlah waktu (jam) yang digunakan untuk menyelesaikan sprint sebanyak 71 jam dengan lama pengerjaan sebanyak 10 hari. Jika pekerjaan diselesaikan sesuai dengan jumlah hari yang ditentukan maka grafik akan mendekati waktu yang ideal dimana garis yang menunjukkan waku ideal berwarna coklat. Proses tahapan sprint yang dilakukan antara sprint pertama hingga sprint terakhir memiliki tahapan yang sama. Hal yang membedakan yaitu pada jumlah waktu yang diperlukan selama pengerjaan dan hambatan dari setiap sprint. Proses yang efisien yaitu ketika dalam mpengerjaanya miliki tingkat efektifitas yang meningkat dari sprint pertama hingga sprint terakhir.

4. Delivery produk
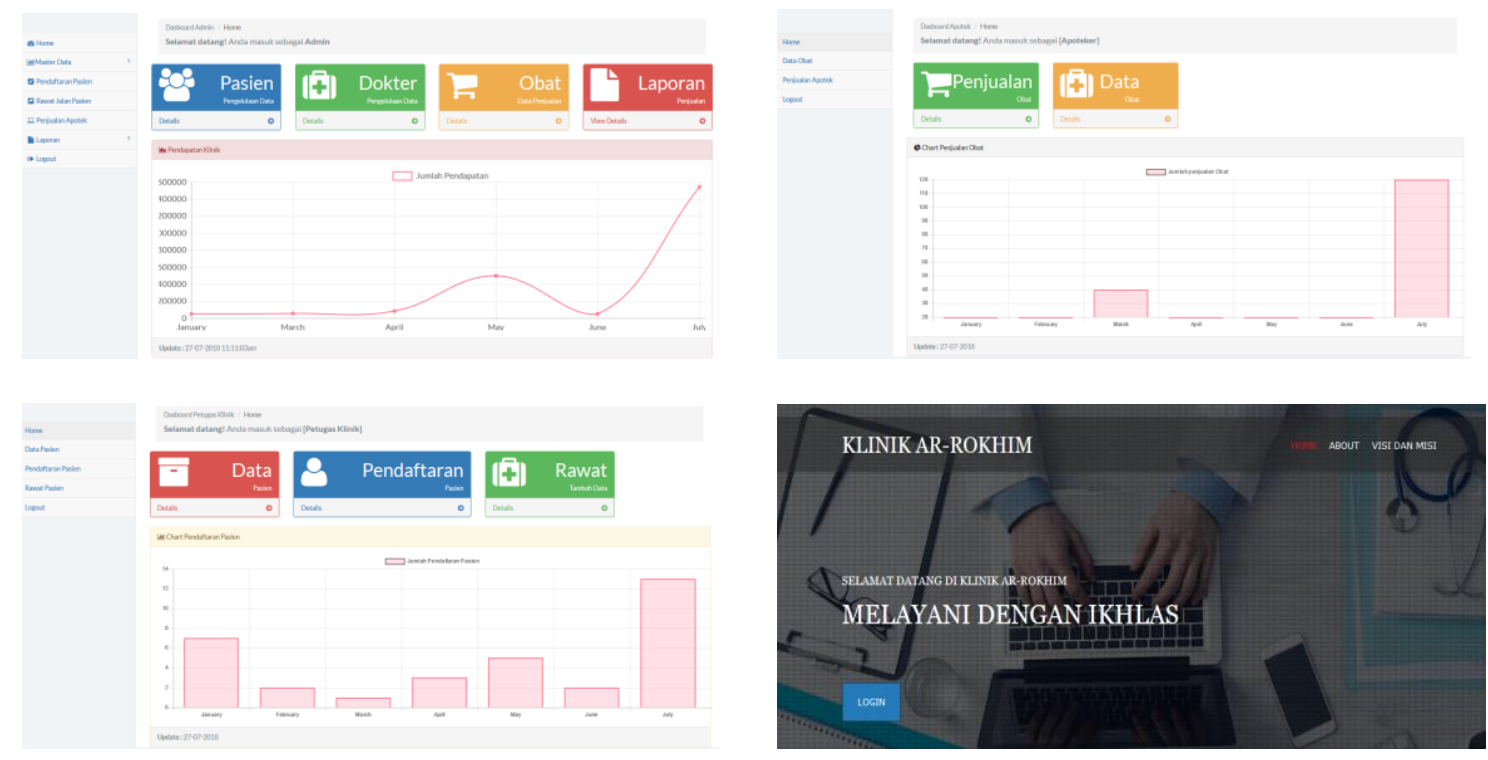

Gambar 4. Halaman Web

Tahap yang terakhir dalam menerapkan metode Scrum yaitu penyajian produk kepada pengguna sistem. Setelah empat sprint selesai dikerjakan dan menghasilkan rilis produk dari masing-masing sprint maka diperoleh produk sistem informasi untuk klinik Ar-Rokhim yang dapat digunkan oleh petugas klinik. Delivey produk menyatakan bahwa produk sudah siap untuk digunakan pada lingkungan klinik dimana tampilan dari sistem tersebut digambarkan pada gambar 4.

\section{KESIMPULAN}

Berdasarkan hasil penelitian yang telah dilakukan, masalah yang dialami oleh klinik ArRokhim yaitu pada manajemen data dan pengembangan sistem yang ada dapat diatasi dengan pemodelan scrum. Hal ini dapat dilihat dari Burndown Chart yang menunjukan kesesuian dengan target waktunya. Dengan demikian, dapat diperoleh kesimpuan bahwa sistem informasi berbasis website yang dibangun menggunakan metode Scrum dapat membantu dalam meningkatkan pelayanan, efektifitas kinerja petugas dan pengelolaan data di klinik Ar-Rokhim. Sistem yang telah dibangun dapat digunakan untuk mengelola data pasien, mengelola data dokter, data petugas, data pendaftaran, menyimpan data rekam medis, menghitung transaksi secara otomatis dan pembuatan laporan. 
Selain itu, metode Scrum yang digunakan menuntut tim untuk memiliki skill yang komplek dalam pengembangan sistem. Setiap anggota tim pengembang dituntut mengetahui peran system analyst, programmer, tester maupun implementor. Hal yang ditekankan pada metode ini ialah komunikasi, baik antara anggota tim maupun dengan pengguna sistem. Dalam menerapkan Scrum memiliki fokus pada fitur pokok yang harus diselesaikan terlebih dahulu. Hal ini memberi efek pada hasil produk lebih fokus untuk menyelesaikan masalah utama.

\section{SARAN}

Saran atau rekomendasi merupakan implikasi hasil penelitian terhadap perkembangan ilmu, teknologi, serta penggunaan praktis. Peneliti memiliki saran untuk pengembangan penelitian selanjutnya, yaitu;

1. Salah satu pelayanan kesehatan dari klinik Ar-Rokhin yaitu rawat inap. Pada penelitian ini hanya sebatas pelayanan rawat jalan. Sehingga perlu adanya penambahan fitur untuk menangani pelayanan rawat inap pasien.

2. Perlu analisa lebih detail mengenai manajemen obat pada apotek.

3. Membuat sistem tidak hanya berbasis website tapi juga berbasis mobile. Hal ini digunakan sebagai daya tarik pasien untuk melakukan perawtan pada klinik Ar-Rokhim.

4. Untuk menerapkan metode Scrum, anggota tim harus saling membantu demi menyelesaikan tujuan sprint yang sedang berlangsung. Selain itu Scrum master perlu membangun suasana tetap positif ketika melakukan evaluasi. Hal ini diperlukan agar tim tetap solid meski ada anggota yang kurang maksimal dalam pengerjaan task. Kemudian, jika metode Scrum digunakan sebagai penelitian dengan tujuan akademis, perlu dikombinasi dengan metode lain yang lebih menekankan pada desain sistem. Sehingga hasil yang diperoleh memiliki desain dan perencanaan yang jelas.

\section{DAFTAR PUSTAKA}

[1] G. Susanto dan S. , "Sistem Informasi Rekam Medis Pada Rumah Sakit Umum Daerah (RSUD)," Journal Speed - Sentra Penelitian Engineering dan Edukasi, vol. 3, no. 4, pp. 18-24, 2011.

[2] D. Iflahah, I. Aknuranda dan N. Y. Setiawan, "Analisis dan Perancangan Sistem Informasi Rekam Medis Poli Gigi (Studi Kasus : Puskesmas Sumbersari Kecamatan Saradan Kabupaten Madiun)," Jurnal Pengembangan Teknologi Informasi dan Ilmu Komputer, vol. 2, no. 6, pp. 2121-2130, 2018.

[3] I. Sommerville, Software Engineering, 10th penyunt., Addison-Wesley, 2015.

[4] N. M. A. Munassar dan A. Govardhan, "A Comparison Between Five Models Of Software Engineering," International Journal of Computer Science Issues, vol. VII, no. 5, pp. 94$101,2010$.

[5] W. Suharso, B. I. Wicaksono dan G. I. Marthasari, "Penerapan Scrum dan Algoritma COCOMO Pada Aplikasi Manajemen Proyek Perangkat Lunak," SATIN - Sains dan Teknologi Informasi, vol. 4, no. 1, pp. 97-104, 2018.

[6] U. Ependi, "Pengembangan E-Trace Alumni Dengan Menggunakan Pendekatan Metode Agile," dalam Seminar Nasional Informatika 2012 (semnasIF 2012), Yogyakarta, 2012. 
[7] R. M. Zaef, N. C. Herbaviana dan A. Chusyairi, "Sistem Informasi Penerimaan Peserta Didik Baru Berbasis Android Menggunakan Metode Agile," dalam Konferensi Nasional Sistem Informasi 2018, Pangkalpinang, 2018.

[8] Y. L. Prasetio, N. Hanafiah, A. Yosanny, C. Yolanda, F. P. Musbar dan D. Septianto, "Pengembangan Aplikasi Penjadwalan Wisata Harian Pada Smartphone Dengan Pendekatan Scrum," ComTech, vol. 5, no. 2, pp. 534-543, 2014.

[9] C. Ebert dan M. Paasivaara, "Scaling Agile," IEEE Software, vol. 34, no. 6, pp. 98-103, November/December 2017.

[10] L. Rising and N. S. Janoff, "The Scrum software development process for small teams," IEEE Software, vol. 17, no. 4, pp. 26-32, July-August 2000.

[11] V. T. Faniran, A. Badru dan A. Ajayi, "Adopting Scrum as an Agile approach in distributed software development: A review of literature," dalam 2017 1st International Conference on Next Generation Computing Applications (NextComp), Mauritius, 2017.

[12] D. P. Harvie dan A. Agah, "Targeted Scrum: Applying Mission Command to Agile Software Development," IEEE Transactions on Software Engineering, vol. 42, no. 5, pp. 476-489, 2016.

[13] R. T. Hans, "Work in Progress - The Impact of the Student Scrum Master on Quality and Delivery Time on Students' Projects," dalam 2017 International Conference on Learning and Teaching in Computing and Engineering (LaTICE), Hongkong, 2017.

[14] K. S. Rubbin, Essential Scrum, United States of America: Pearson Education, 2013.

[15] A. S. S. Wijaya, L. S. Lawunugraha dan I. A. Iswanto, "Perancangan Sistem Informasi Manajemen Pada Klinik Skala Kecil (Studi Kasus: Klinik Dr. Jonni)," ComTech, vol. 5, no. 2, pp. 1059-1072, 2014.

[16] M. P. Kumara, A. P. Utomo dan F. Nugraha, "Sistem Informasi Manajemen Klinik Permata Medical Center Pati," dalam Pros iding SNATIF Ke -2 , Kudus, 2015.

[17] S. Ramadhani, U. Anis dan S. T. Masruro, "Rancang Bangun Sistem Informasi Geografis Layanan Kesehatan Di Kecamatan Lamongan Dengan PHP MySQL," Jurnal Teknika, vol. 5, no. 2, pp. 479-483, 2013. 